\title{
Energy absorption capability and deformation of laminated panels for armoured vehicle materials
}

\section{N.A. Rahman ${ }^{1 *}$, S. Abdullah ${ }^{1,2^{*}}$, M.F. Abdullah ${ }^{1}$, W.F.H. Zamri ${ }^{1}$, M.Z. Omar ${ }^{1}$ and Z. Sajuri ${ }^{1}$}

${ }^{1}$ Department of Mechanical and Materials Engineering, Faculty of Engineering and Built Environment, Universiti Kebangsaan Malaysia, 43600 Bangi, Selangor, Malaysia,

${ }^{2}$ Centre for Automotive Research, Faculty of Engineering and Built Environment, Universiti Kebangsaan Malaysia, 43600 Bangi, Selangor, Malaysia. Phone: +60389118011; Fax: +60389118315

*Email: najihah.ar@gmail.com; shahrum@ukm.edu.my

\begin{abstract}
This paper investigates the computational-based deformation and energy absorption capability of laminated metal panels composed of high-strength steel and aluminium alloy under low-velocity impact. Layering aluminium alloy plates with high-strength steel has become of interest for reducing the overall density of armoured vehicle bodies while improving the ballistic resistance. In order to enhance the attractiveness of laminated plate construction, it is essential to study the strength of the two different metals in a laminated panel under low-velocity impact before performing a ballistic impact. Two types of laminated panels were constructed: two-layer and three-layer configurations. Both were oriented transverse to the loading axis and solved using quasi-static analysis. The deformation behaviour of these panels was studied and the energy absorption capacities were quantified. The results showed that the energy absorption capacities of the laminated panels were on average $220 \%$ higher in the three-layer configuration panels compared to in the two-layer configuration panels. The deformation lengths in the three-layer configuration panels were on average $22 \%$ smaller than those of the two-layer configuration panels with $25 \%$ to $30 \%$ weight reduction. The best three-layer configuration panel will be used later for investigating a suitable combination panel for armoured vehicles subjected to ballistic impact.
\end{abstract}

Keywords: Deformation; energy absorption; laminated panel; quasi-static analysis.

\section{INTRODUCTION}

The current trend in the military industry is to integrate lightweight materials into armoured vehicle designs to reduce vehicle weight in order to improve fuel consumption efficiency and manoeuvrability, without compromising the performance and safety. The decrease in vehicle weight cannot reduce passenger safety. Therefore, the materials used in the manufacturing cannot compromise the stiffness and strength. When developing new armoured vehicle panels, structural crashworthiness must also be considered because force transmissions are closely related to the deformation and energy absorption capability of the panels [1]. Thus, it is important to properly determine the behaviour and properties of new materials to be used in these vehicles. Incorporating existing materials with lightweight materials such as composites, aluminium foam and aluminium alloys 
has become of interest nowadays [2-4]. Aluminium and its alloys are among materials widely used to achieve lightweight construction and improve vehicle crashworthiness. These materials have high stiffness-to-weight ratios, good formability, good corrosion resistance and recycling potential, which make them appropriate candidates for integration with the existing high-density armour steel [5]. It has been observed that aluminium has some weaknesses compared to high-strength steel when dealing with structural impact. Since aluminium plates have poor ballistic performance, they are often utilised in multi-layered or spaced structures in combination with other materials $[6,7]$.

The experimental approach can provide good perforation results, but it is very expensive. On the other hand, computer simulation has been proven to be a powerful and economical tool for the prediction of the deformation and penetration of laminated panels $[8,9]$. In recent years, many scholars have concentrated on using the finite element method to study the behaviour of developed panels (Nair et al., 2013; Ramadhan et al., 2013). They integrated light materials, such as composites and aluminium alloys, with existing armoured steel to reduce the weight. It has been demonstrated that the use of aluminium and its alloys offers considerable potential for reducing the weight of an armoured vehicle body. Flores-Johnson et al. (2011) concluded in their paper that multilayered mixed plates of high-strength steel and AA7075-T6 have the potential for use in protective structures based on their ballistic experiment and simulation. AA7075-T6 and AA5083-H116 can be integrated with armoured steel to serve as vehicle protective structures [10]. Besides being studied as ballistic resistive structures, aluminium alloy has been widely studied as an energy-absorbing material for thin wall structures. Rao et al. (2012) conducted a series of experiments to study the crashworthiness behaviour of aluminium alloy and high-tensile steel under low impact velocity and found that laminated high-tensile steel and aluminium alloy can increase the energy absorption of a structure [11]. Abassi et al. (2015) also found that laminated high-strength steel and aluminium alloy can improve energy absorption capability of a box structure under low velocity impact [12].

The main criterion for armoured vehicle performance is its ballistic impact resistant capability resulting from high velocity impact by a low mass projectile. The materials used in the laminated panel must also not compromise the stiffness and strength of the vehicle panel in both low- and high-velocity impacts because structural resistance to severe impacts is directly related to structural integrity [13]. Structural performance in low velocity must also be considered because force transmissions between layers in laminated panels are related closely with the deformation and energy absorption capability of the panels [1]. Thus, it is essential to better understand the local strength and energy-absorbing characteristics of developed laminated panels in order to determine the behaviour and properties of new panels to be used in these vehicles in terms of their strength during low-velocity impacts while considering high-velocity impacts, such as ballistic impacts. Since armoured vehicles are also subjected to crashes and unwanted flying debris during service, it becomes crucial to study the crashworthiness of the structures in terms of energy absorption and deformation upon low velocity impact. The objective of this study is to investigate the energy absorption for two- and three-layer laminated panels consisting of high-strength steel and aluminium alloy. In this work, quasi-static three-point bending tests were performed using an explicit non-linear finite element programme to analyse the deformation and energy absorption. A series of simulations for different thicknesses of high-strength steel and aluminium panels was conducted to analyse the effects. 


\section{MATERIALS AND METHODS}

The methodology framework used in this study is given in Figure 1. Combining two different metals of Ar500 steel and Al7075-T6 aluminium is an interesting option leading to weight-saving and impact-resistance improvements based on their material properties in terms of hardness and tensile strength. Therefore, firstly tensile and hardness tests were conducted to find the properties of these materials. The cross section and the length of the gauge area were $6 \times 6 \mathrm{~mm}^{2}$ and $25 \mathrm{~mm}$, respectively. The tensile test was performed based on the ASTM E8 and the sample was strained at a cross head speed of $1.5 \mathrm{~mm} / \mathrm{min}$ to obtain the stress-strain curve for mechanical properties analysis. A Rockwell hardness tester was used for B scale hardness measurement of the tested materials. The Rockwell scale is a hardness scale based on the indentation hardness of a material. Then, the computational method was executed using the material properties found from the tensile test.

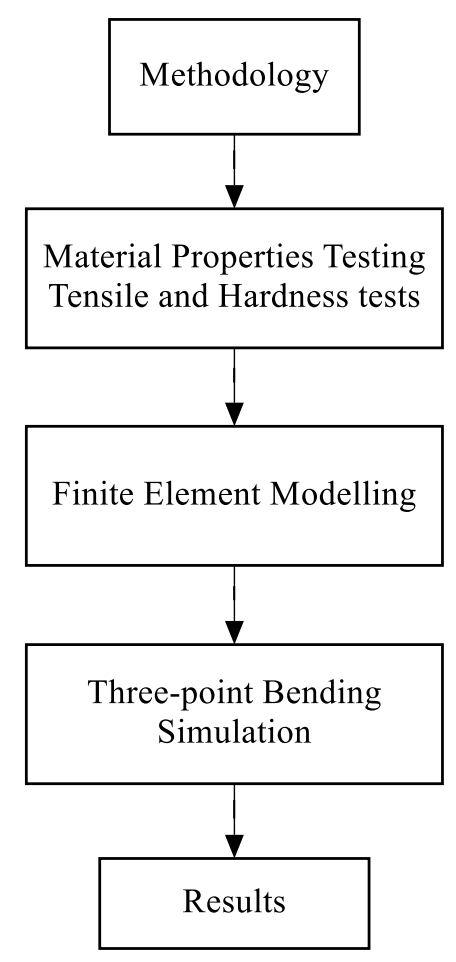

Figure 1. Flow diagram of methodology used.

\section{Crashworthiness Parameters}

As a type of important lightweight structural components, laminated panels have gained popularity in automotive industry applications. The structural crashworthiness signifies an important mechanical property under impact loadings and it was found to vary significantly with changes to parameters such as laminate layer thickness and density [14]. By definition, the crashworthiness is the ability of a structure to absorb impact energy with minimal attenuation of survivable space. It can be evaluated by several criteria, such as energy absorption (EA) and specific energy absorption (SEA). EA is the total strain energy absorbed during deformation and can be calculated from the curve of force-deflection. It is defined in Eq. 1 [15]. 


$$
E A(d)=\int_{0}^{d} F(x) d x
$$

where $d$ is deformed length and $F(x)$ is the instantaneous load, which can be extracted directly from the simulation data. Specific energy absorption (SEA) is represented as the absorbed energy $(E A)$ per structure mass $\left(M_{t}\right)$ and is given by Eq. 2 :

$$
S E A=E A / M_{t}
$$

SEA is one of the most important factors in the design of structures of vehicles where the weight efficiency is the main consideration and has often been taken as the design criteria for lightweight requirements. A higher SEA indicates greater efficiency of the panels in terms of energy absorption capability [15].

\section{Computational Modelling}

For any commercial software, the simulation is usually set up using the procedure shown in Figure 2. Table 1 shows the material properties of the two materials used in constructing the laminated panels in FE modelling. The first and third layers are made of high-strength steel (HSS) and the second layer is made of aluminium alloy, AA7075-T6. The contact employs a non-linear surface-to-surface formulation to define the contact of various interacting surfaces. In the computational approach, contact is the most essential part of crashworthiness analysis as it defines the interaction between rigid bodies [16]. The impenetrability condition is checked and the kinematic constraint is used to simulate the interface between the first and second layers, and the second and third layers. Since HSS is much harder than AA7075-T6, the kinematic constraint helps to strictly enforce the contact constraint to prevent the soft material from penetrating the hard material during the deformation process. All models are subjected to symmetry boundary conditions as the model geometries and restraints are symmetrical about a plane and it reduces the analysis run time and memory required.

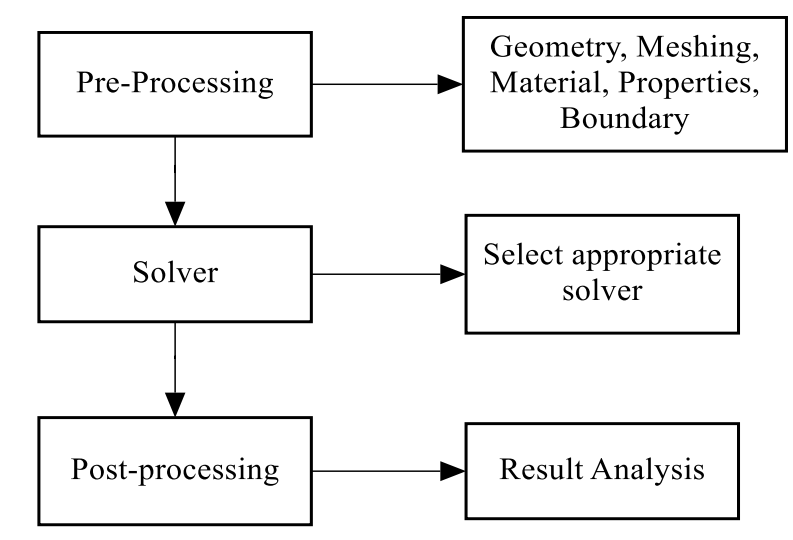

Figure 2. Typical FEA procedure for commercial software.

The nonlinear explicit finite element programme of a commercial software package was used to predict the deformation and energy absorption capability of the laminated panels. Explicit codes are best suited for incorporation of various material laws into an analysis and are usually preferred when dealing with inelastic constitutive equations [17]. The geometry considerations are summarised in Table 2 and are illustrated 
in Figure 2. Case studies 1 to 5 represent the two-layer configurations and case studies 6 to 10 represent the three-layer configurations. Materials for the first and second layers are HSS and AA7075-T6, respectively. The third layer is designated as HSS for the threelayer configuration only, in which the first layer thickness from case studies 1 to 5 is divided into two layers. The important factor in the sample size is its thickness because the selected thickness of $25 \mathrm{~mm}$ is the standard thickness of existing armour panels. Each layer thickness was set accordingly to a range of 20-30\% weight reduction from the original armour panel to ensure the body stays on the ground during extreme conditions. Figures 2 and 3 show the two- and three-layer configuration panels, respectively. A concentrated load was given for both conditions on the first layer until $100 \mathrm{kN}$ at a rate of $0.4 \mathrm{~m} / \mathrm{s}$. The load was set at $100 \mathrm{kN}$ in line with the machine available for subsequent experiments. The velocity was set at $0.4 \mathrm{~m} / \mathrm{s}$ to ensure the structure slowly deformed with negligible inertia force and kinetic energy to achieve a quasi-static loading state [18].

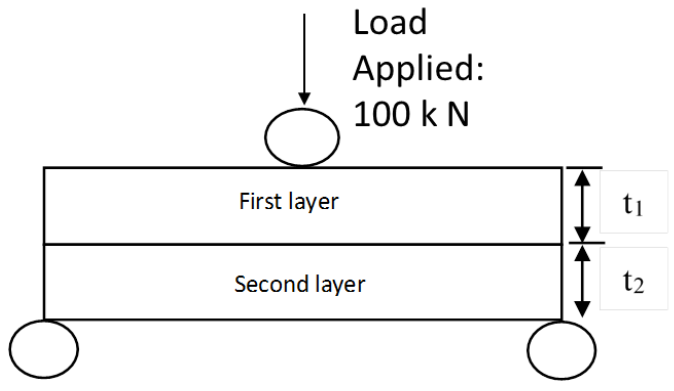

(a)

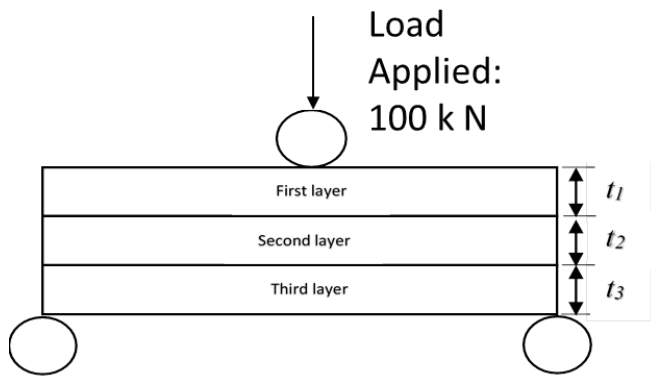

(b)

Figure 3. Schematic layout of three-point bending test for (a) two-layer configuration panel and (b) three-layer configuration panel.

Table 1. Material properties of laminated panels.

\begin{tabular}{cccccc}
\hline & $\rho\left(\mathrm{g} / \mathrm{cm}^{3}\right)$ & $E(\mathrm{GPa})$ & $v$ & $\sigma_{y}(\mathrm{MPa})$ & $\sigma_{u}(\mathrm{MPa})$ \\
\hline High-strength steel & 7.860 & 7.69 & 0.30 & 1.25 & 76.9 \\
AA7075-T6 & 2.804 & 2.69 & 0.33 & 0.48 & 26.9 \\
\hline
\end{tabular}

Table 2. Geometrical parameters of case studies.

\begin{tabular}{ccccc}
\hline Case study & $t_{1}(\mathrm{~mm})$ & $t_{2}(\mathrm{~mm})$ & $t_{3}(\mathrm{~mm})$ & Mass reduction $(\%)$ \\
\hline 1 & 13 & 12 & 0 & 30 \\
2 & 14 & 11 & 0 & 28 \\
3 & 15 & 10 & 0 & 25 \\
4 & 16 & 9 & 0 & 23 \\
5 & 17 & 8 & 0 & 20 \\
6 & 7 & 12 & 6 & 30 \\
7 & 7 & 11 & 7 & 28 \\
8 & 8 & 10 & 7 & 25 \\
9 & 8 & 9 & 8 & 23 \\
10 & 9 & 8 & 8 & 20 \\
\hline
\end{tabular}




\section{RESULTS AND DISCUSSION}

The results from the experimental tensile tests are provided in Figure 4 where the tensile strengths of HSS and AA7075-T6 are $1687 \mathrm{MPa}$ and $545 \mathrm{MPa}$, respectively. A slight difference in the elongation of these materials was observed, where HSS exhibits $12.1 \%$ and AA7075-T6 is $11.8 \%$. HSS possesses a very high hardness of 114 HRB while AA7075 has a hardness of $84 \mathrm{HRB}$. A summary of the mechanical properties of the highstrength steel and the aluminium alloy is given in Table 3. Because of the limitation of universal testing equipment to perform a bending test of a thick layer of HSS with high hardness and ultimate strength, the computational method is one of best options to be utilised in order to study the deformation and energy absorption capabilities of the developed laminated panels.

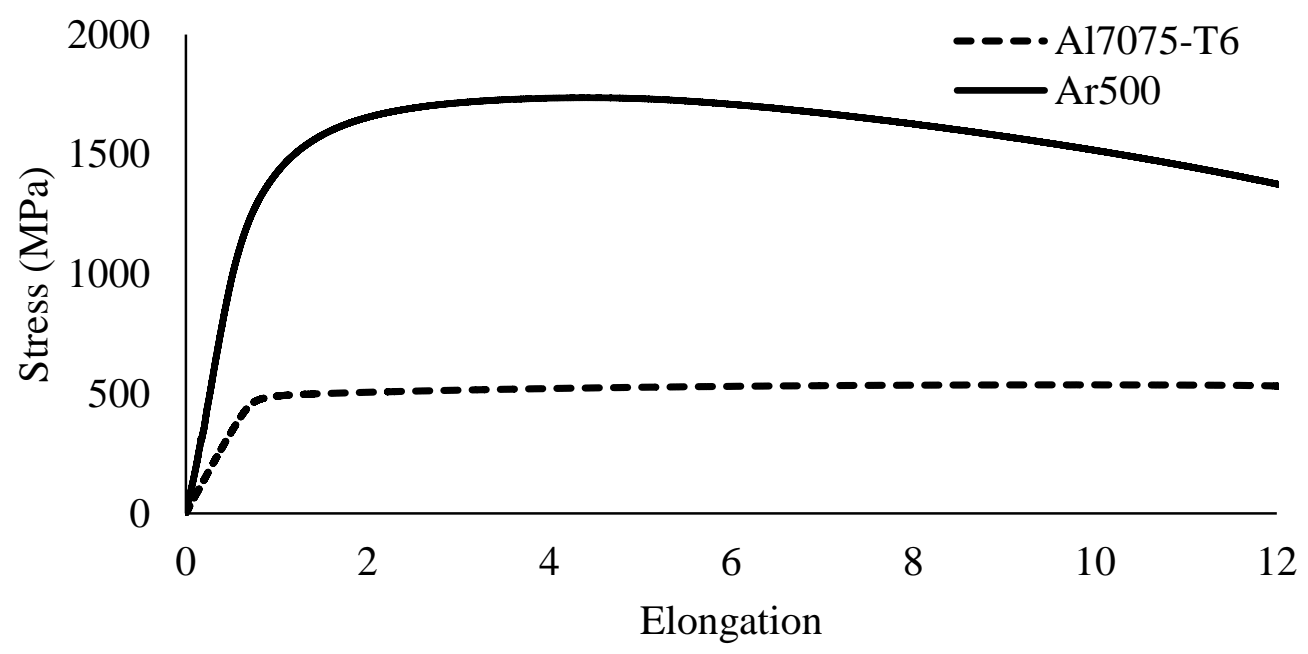

Figure 4. Stress-strain curves for HSS and AA7075-T6 at $1.5 \mathrm{~mm} / \mathrm{min}$.

Table 3. The mechanical properties of Hardox 500 and Al7075-T6.

\begin{tabular}{cccccc}
\hline Material & $\begin{array}{c}\text { Density } \\
\left(\mathrm{kg} / \mathrm{m}^{3}\right)\end{array}$ & $\begin{array}{c}\text { Hardness } \\
(H R B)\end{array}$ & $\begin{array}{c}\text { Tensile } \\
\text { strength } \\
(\mathrm{MPa})\end{array}$ & $\begin{array}{c}\text { Yield } \\
\text { strength } \\
(\mathrm{MPa})\end{array}$ & $\begin{array}{c}\text { Elongation } \\
\text { at break }(\%)\end{array}$ \\
\hline HSS & 7850 & 105 & 1687 & 1410 & 12.1 \\
AA7075-T6 & 2804 & 84 & 545 & 472 & 11.8 \\
\hline
\end{tabular}

The crashworthiness behaviour of laminated panels was studied using a commercial software programme. It is recommended that the ratio of kinetic energy (ALLKE) to internal energy (ALLIE) be small and that ALLKE should not exceed 5\% of the ALLIE (Abaqus-Inc, 2014). ALLIE is the internal energy of the material caused by elastic and plastic strain energy and ALLKE is the kinetic energy of the material caused by motion. Figure 5 shows that ALLKE is small enough to indicate that the meshing is refined enough for quasi-static explicit simulation. The kinetic energy of the deforming panels should exceed a small fraction of its internal energy through the majority of a quasi-static analysis to ensure that the rate of panel deforming did not dominate the response. The response should be at the slowest mode without inertia force effect [18]. 


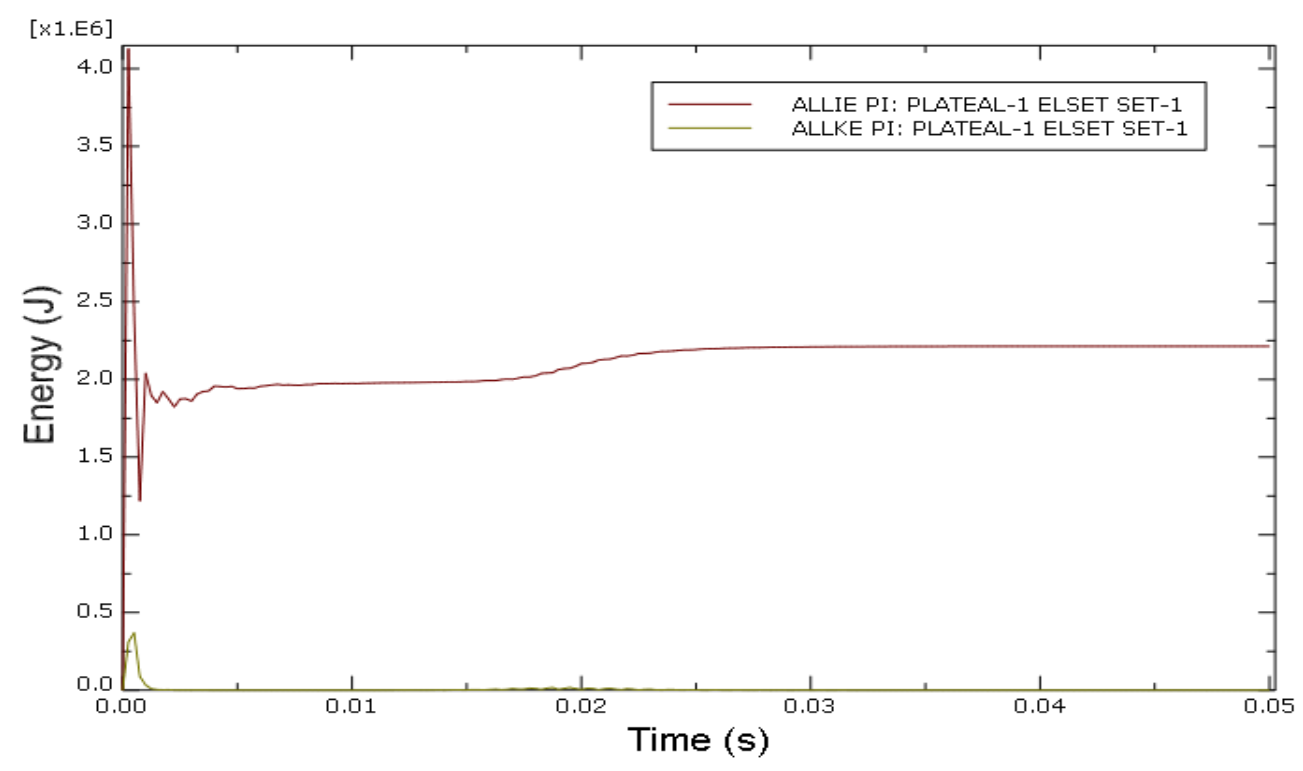

Figure 5. Distribution of internal and kinetic energy for the simulation.

Figures 6 and 7 show the initial condition and deformation patterns for twoconfiguration panels and three-layer configuration panels, respectively. Figure 8 shows the deformation lengths of each case resulting from $100 \mathrm{kN}$ loading at $0.4 \mathrm{~m} / \mathrm{s}$. Cases $1-$ 3 as in Figures $6 \mathrm{f}-\mathrm{h}$ show decrements in deformation lengths by an average of $14 \%$ as the layer 1 thickness increased by $1 \mathrm{~mm}$ and the layer 2 thickness decreased by $1 \mathrm{~mm}$. When the layer 1 thickness further increased by $1 \mathrm{~mm}$ and layer 2 thickness decreased by $1 \mathrm{~mm}$ (as in cases 4-5) in Figures 6i-j, the deformation lengths increased abruptly by $160 \%$ and caused the layer 2 to fail, which can be seen in Figure 9 from the large decrement in specific energy absorption by an average of $96 \%$. This is the undesirable behaviour of system overloading, which caused the extreme plastic strain leading to structural failure and ineffective energy dissipation process [18-20]. The failures of cases 4 and 5 happen because layer 2 could not withstand the weight and strength of layer 1, which is three times its weight and ultimate strength. The top layer with much larger weight and hardness acted as an impactor to the softer bottom layer.

The three-layer configurations have been analysed to compare their deformations and energy absorption capabilities with the two-layer configurations. Three-layer configurations (cases $6-10$ ) as in Figures $7 \mathrm{f}-\mathrm{j}$ are similar to the two-layer configurations (cases 1-5) in terms of the total thickness of the two materials. The deformation lengths of all three-layer cases show average decrements of $6.7 \%$ when the lengths of layer 1 and 3 increased by $1 \mathrm{~mm}$ and layer 2 decreased by $1 \mathrm{~mm}$. Three-layer configuration panels are more efficient in absorbing the impact energy, which can be seen from Figure 9 where the specific energy absorptions of three-layer configuration (cases 6-8) are two to three times higher than the two-layer configuration panels (cases 1-3) as in Figures $6 f-h$. Moreover, cases 9 and 10 which possess, the same thickness of layer 2 as with cases 4 and 5, have deformed without failure at layer 2 . This trend is probably owing to the higher amount of energy being absorbed by the AA7075-T6 in layer 2 and being dissipated very well by the system as a whole, as described in Figure 6 . As such, the configuration layers played an important role in controlling the amount of energy being absorbed by the laminated panels. It can be seen that the maximum amount of SEA was recorded for the panels that had the largest thickness of AA7075-T6 and the smallest thickness of HSS. 


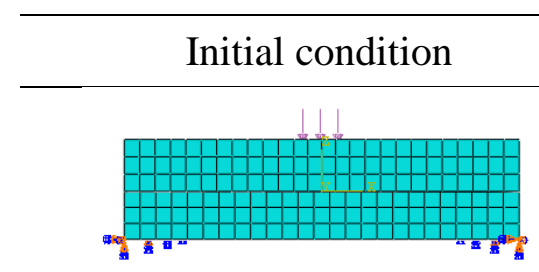

(a)

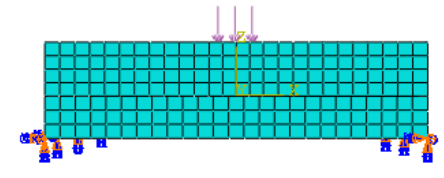

(b)

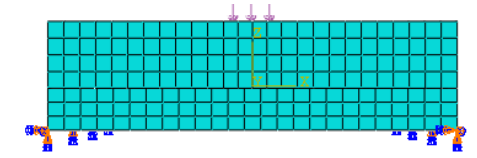

(c)

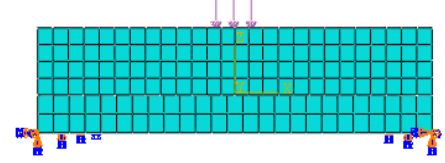

(d)

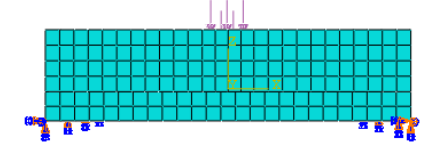

(e)

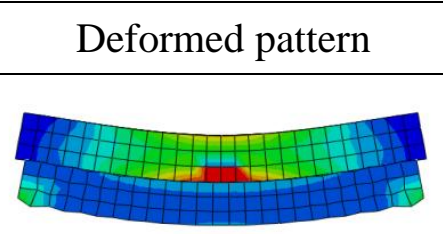

(f)

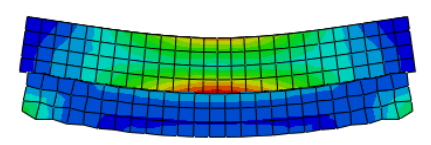

$(\mathrm{g})$

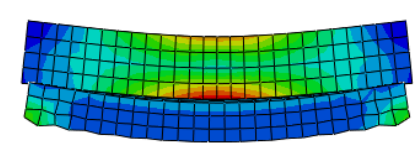

(h)

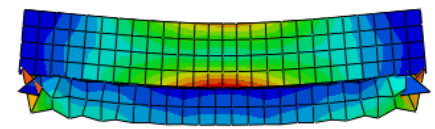

(i)

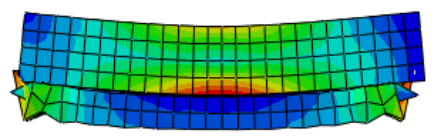

(j)

Figure 6. Initial conditions of (a) case study 1, (b) case study 2, (c) case study 3, (d) case study 4, (e) and case study 5. Deformation patterns of (f) case study 1 , (g) case study 2, (h) case study 3, (i) case study 4 and (j) case study 5, for two layer configuration panels.

The SEA is related to the deformation length, by which the energy is absorbed by the panel through its deformation behaviour. According to Eq. 1 and Eq. 2, as the deformation length increased, the SEA also increased. All cases except for cases 3 and 4 followed this relationship. The two highest deformation lengths were $16 \mathrm{~mm}$ and $19 \mathrm{~mm}$, and the two lowest $S E A$ values were $0.42 \mathrm{~kJ} / \mathrm{kg}$ and $0.98 \mathrm{~kJ} / \mathrm{kg}$ for cases 4 and 5 respectively, which caused them to fail. Both of them are two-layer configuration panels where the AA7075-T6 was on the bottom layer. Other than these cases, the highest SEA of $32.27 \mathrm{~kJ} / \mathrm{kg}$ was found for case 7 . Case 7 is a three-layer configuration where AA7075T6 is in the middle layer. These results show that AA7075-T6 can absorb energy better when it is placed in the middle layer rather than on the bottom layer. Owing to the very high-strength and high-hardness steel as the front layer, the energy was mostly absorbed by the front layer and created a marginal stress effect on the Al7075-T6 as the second layer [21-23]. The conformity of the deformation pattern of the projectile during impact on both double-layered and triple-layered plates for the numerical results still needed to be done with the experimental results. Scaling of panel thickness should be considered with regards to the high hardness and strength of HSS, and the limitations of the laboratory equipment. 


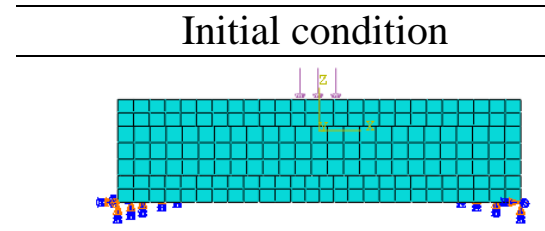

(a)

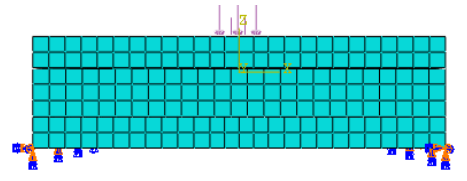

(b)

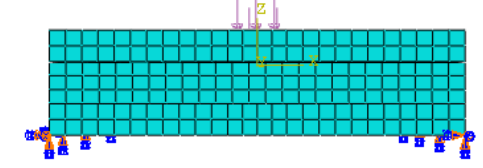

(c)

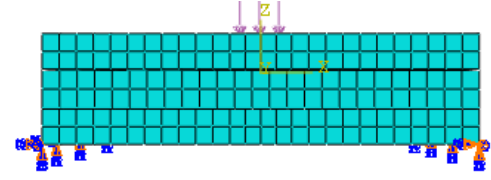

(d)

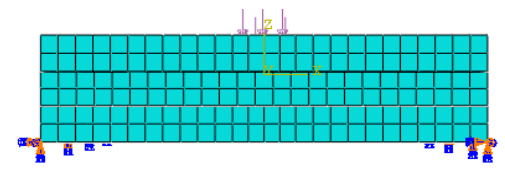

(e)

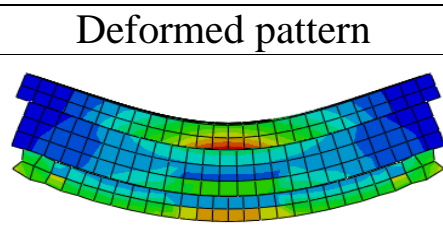

(f)

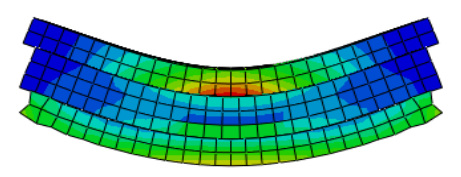

(g)

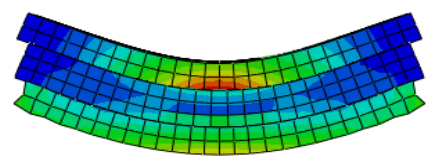

(h)

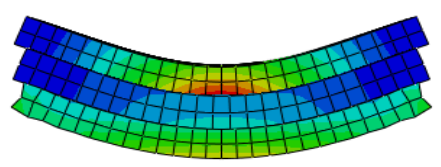

(i)

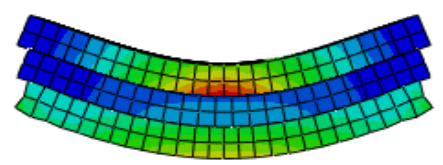

(j)

Figure 7. Initial conditions of (a) case study 6, (b) case study 7, (c) case study 8 , (d) case study 9 and (e) case study 10, and the deformation patterns of (f) case study 6 , (g) case study 7, (h) case study 8, (i) case study 9 and (j) case study 10 for three-layer configuration panels.

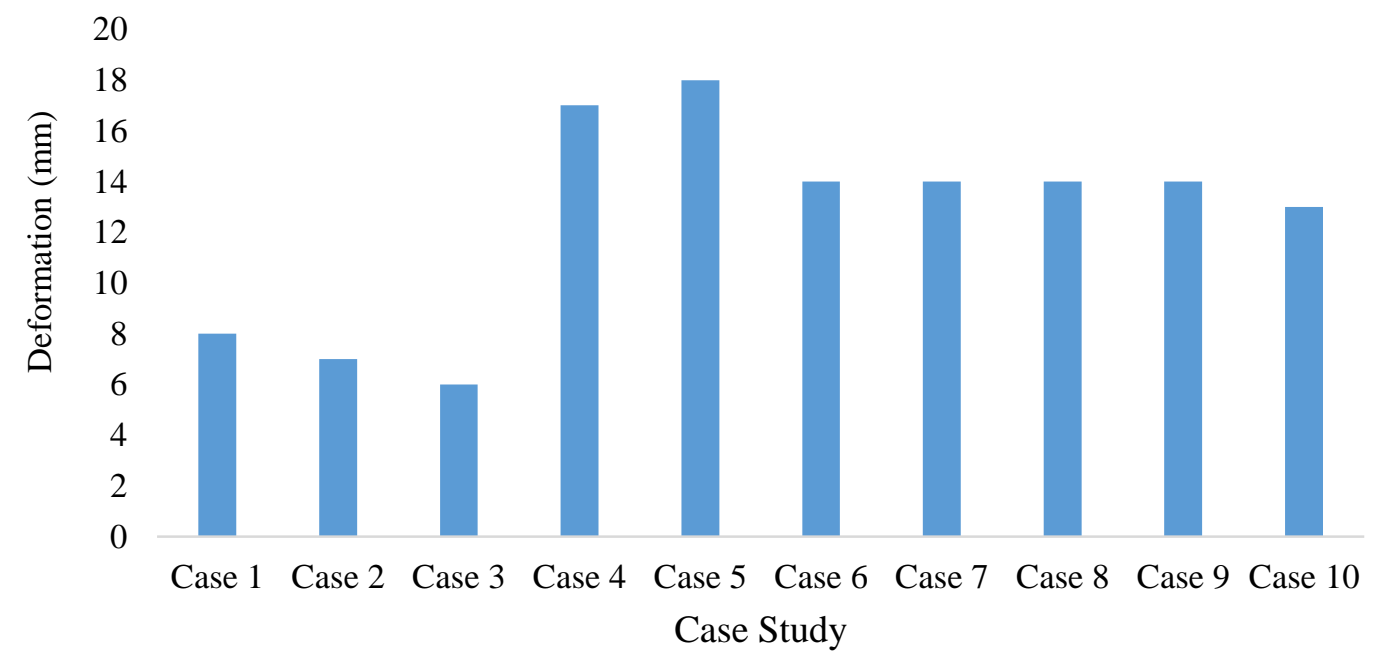

Figure 8. Deformation length for each case study. 


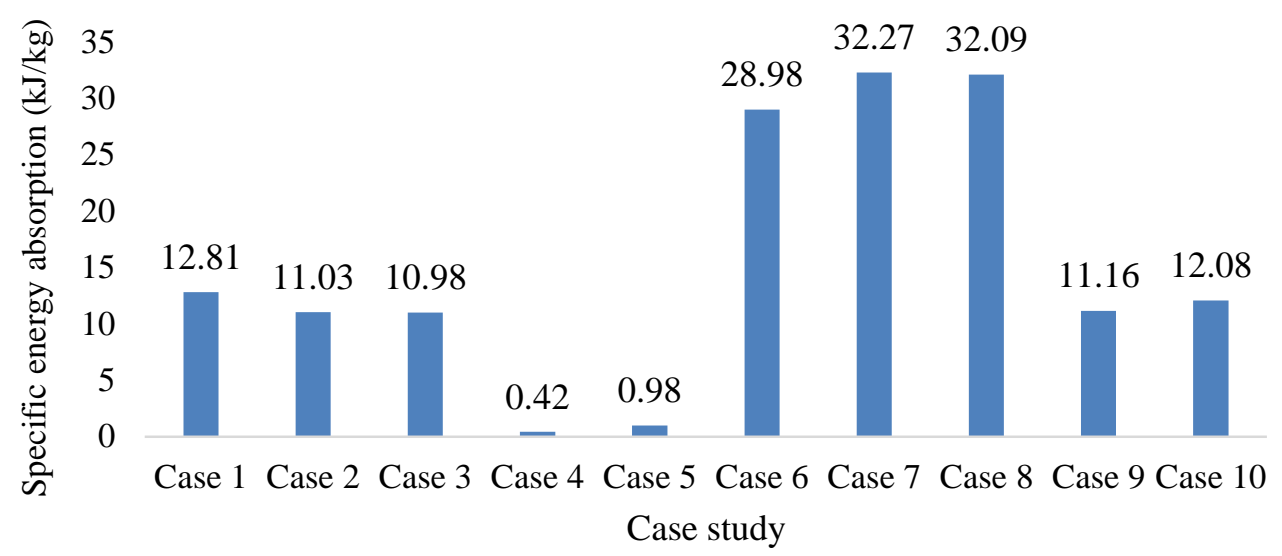

Figure 9. Specific energy absorption for each case study.

\section{CONCLUSIONS}

This paper facilitates the selection of appropriate parameters for laminated panels of highstrength steel and AA7075-T6 to withstand low-velocity impacts. Two- and three-layer configuration panels were modelled through the FE programme. Different layer thicknesses of laminated panels produced different deformation and SEA effects. Small changes in this parameter resulted in large changes in deformation and SEA values. The changes in performance of the two-layer configuration panels for combinations of layer 1 with thickness less than $15 \mathrm{~mm}$ and layer 2 with thickness more than $10 \mathrm{~mm}$ were small compared to the two-layer configuration panels with layer 1 thickness more than $15 \mathrm{~mm}$ and layer 2 thickness less than $10 \mathrm{~mm}$, where failure occurred. The first layer of the twolayer configuration panel acted as an impactor to the second layer and caused damage to the second layer as in cases 4 and 5. Meanwhile, the three-layer configuration panels had relatively large deformation to allow high energy absorption, but steadily deformed without failure. The three-layer configuration panels are able to absorb impact energy better than two-layer configuration panels and thus performed better in terms of energy absorption capability and deformation for survivability. Thus, three-layer configuration panels seem to be a suitable combination for use in armoured vehicles.

\section{ACKNOWLEDGEMENTS}

The authors wish to express their gratitude to Ministry of Higher Education Malaysia via Universiti Kebangsaan Malaysia and Universiti Pertahanan Nasional Malaysia under research funding LRGS/2013/UPNM-UKM/DS/04 for supporting this research project

\section{REFERENCES}

[1] Jing L, Xi C, Wang Z, Zhao L. Energy absorption and failure mechanism of metallic cylindrical sandwich shells under impact loading. Material and Design. 2013:470-80.

[2] Abdullah MF, Abdullah S, Rahman NA, Risby MS, Omar MZ, Sajuri Z. Improvement of high velocity impact performance of carbon nanotube and lead 
reinforced magnesium alloy. International Journal of Automotive and Mechanical Engineering. 2016;13:3423-33.

[3] Børvik T, Forrestal MJ, Hopperstad OS, Warren TL, Langseth M. Perforation of AA5083-H116 aluminium plates with conical-nose steel projectiles Calculations. International Journal of Impact Engineering. 2009;36:426-37.

[4] Nasirzadeh R, Sabet AR. Study of ofam density variations in composite sandwich panels under high velocity impact loading. International Journal of Impact Engineering. 2014;63:129-39.

[5] Miller WS, Zhuang L, Bottema J, Witterbrood AJ, De Smet P, Haszler A, et al. Recent development in aluminium alloys for the automotive industry. Material Science and Engineering: A. 2000:37-49.

[6] Flores-Johnson EA, Saleh M, Edwards L. Ballistic performance of multi-layered metallic plates impacted by a 7.62-mm APM2 projectile. International Journal of Impact Engineering. 2011;38:1022-32.

[7] Rahman NA, Abdullah S, Zamri WFH, Abdullah MF, Omar MZ, Sajuri Z. Ballistic limit of high-strength steel and Al7075-T6 multi-layered plates under 7.62-mm Armour Piercing Impact. Latin American Journal of Solids and Structures. 2016;13:1658-76.

[8] Erice B, Pérez-Martín MJ, Gálvez F. An experimental and numerical study of ductile failure under quasi-static and impact loadings of Inconel 718 nickel-base superalloy. International Journal of Impact Engineering. 2014;69:11-24.

[9] Kiliç N, Ekici B. Ballistic resistance of high hardness armor steels against 7.62 mm armor piercing ammunition. Material and Design. 2013;44:35-48.

[10] Forrestal MJ, Børvik T, Warren TL. Perforation of 7075-T651 Aluminum Armor Plates with 7.62 mm APM2 Bullets. Experiment Mechanics. 2010;50:1245-51.

[11] Rao KK, Rao KJ, Sarwade AG, Chandra MS. Strength analysis on honeycomb sandwich panels of different materials international Journal of Engineering Research and Application. 2012:365-74.

[12] Abbasi M, Reddy S, Ghafari-Nazari A, Fard M. Multi-objective crashworthiness optimization of multi-cornered thin-walled sheet metal members. Thin-walled Structures. 2015:31-41.

[13] Hou W, Zhu F, Lu G, Fang DH. Ballistic impact experiments of metallic sandwich panels with aluminium foam core. International Journal of Impact Engineering. 2010;37:1045-55.

[14] Børvik T, Hopperstad OS, Reyes A, Langseth M, Solomos G, Dyngeland T. Empty and foam-filled circular aluminium tubes subjected to axial and oblique quasistatic loading. International Journal of Crashworthiness. 2003;8:481-94.

[15] Alkabir MFM, Sapuan SM, Nuraini AA, Ishak MR. Effect of geometry on crashworthiness parameters of natural kenaf fibre reinforced composite hexagonal tubes. Material and Design. 2014:85-93.

[16] Hou R, Long Q, Yang X, Li W. Design optimization of regular hexagonal thinwalled columns with crashworthiness criteria. Finite Element Analysis and Design. 2007;43:555-65.

[17] Huzni S, Ilfan M, Sulaiman T, Fonna S, Ridha M, Arifin AK. Finite element modeling of delamination process on composite laminate using cohesive elements. International Journal of Automotive and Mechanical Engineering. 2013;7:1023-30. 
[18] Baroutaji A, Morris E, Olabi AG. Quasi-static response and multi-objective crashworthiness optimization of oblong tube under lateral loading. Thin-walled Structures. 2014:262-77.

[19] Feli S, Asgari MR. Finite element simulation of ceramic/composite armor under ballistic impact. Composite Part B Engineering. 2011;42:771-80.

[20] Singh R. Process capability study of a rapid casting solution for aluminium alloys using three-dimensional printing. International Journal of Automotive and Mechanical Engineering. 2011;4:397-404.

[21] Ramadhan AA, Abu Talib AR, Mohd Rafie AS, Zahari R. High velocity impact response of Kevlar-29/epoxy and 6061-T6 aluminium laminated panels. Material and Design. 2013:307-21.

[22] Manes A, Lumassi D, Giudici L, Giglio M. An experimental-numerical investigation on aluminium tubes subjected to a ballistic impact with soft core 7.62 ball projectile. Thin-walled Structures. 2013;73:68-80.

[23] Padersen KO, Børvik T, Hopperstad OS. Fracture mechanisms of aluminium alloy AA7075-T651 under various loading conditions. Material and Design. 2011;37:97-107. 